\title{
Impact of clinical pharmacist on medication adherence among psoriasis patients: A randomized controlled study
}

\author{
Aishwarya C. Hiremath ${ }^{a}$, Ramesh Bhandari ${ }^{a}$, Shashikala Wali, Assistant Professor ${ }^{\text {a, }}$, M. \\ S. Ganachari ${ }^{\text {a, }}$ Bhavana Doshi ${ }^{\mathrm{b}}$ \\ ${ }^{a}$ Department of Pharmacy Practice, KLE College of Pharmacy, A Constituent Unit of KLE Academy of Higher Education and Research (KAHER), Belagavi, Karnataka, \\ India \\ ${ }^{\mathrm{b}}$ Department of Dermatology, J N Medical College, A Constituent Unit of KLE Academy of Higher Education and Research (KAHER), Belagavi, Karnataka, India
}

\section{A R T I C L E I N F O}

\section{Keywords:}

Adherence

Patient education

Pharmaceutical CARE

Pharmacist physician issues

Psoriasis

Dermatology

\begin{abstract}
A B S T R A C T
Background: Psoriasis is a chronic inflammatory disease and requires long term management due to which patients become non-adherent to the therapy. Hence this study aims to assess the impact of clinical pharmacists to improve medication adherence in patients with psoriasis.

Materials and methods: This is a randomized controlled study conducted at a tertiary care teaching hospital in the dermatology department, among 68 patients. Aged 18-65 years from the outpatient department diagnosed with psoriasis disease and on treatment were enrolled in the study. Patients with multiple co-morbidities like HIV, hepatitis B/C, and vulnerable populations like lactating and pregnant women are excluded from the study. Enrolled patients are then randomized after taking the Informed consent form. The interventional groups of patients were provided with a patient information leaflet and pharmacist education and counselling along with standard care. Medication adherence of the patients was evaluated at the baseline level to the follow-up after 1 month. Results: Total of 68 were enrolled in the study, out of which 63 completed the study. There was no difference observed at the pre-test in both the groups. After the intervention, there was a significant difference in the experimental group after post-test $(U=200.00, p=0.0001)$. Adherence was improved in the experimental group.

Conclusion: There is a need for clinical pharmacists in providing the patients with knowledge about long term disease management like psoriasis. The implement of specialty pharmacists in dermatological disorders is an excellent choice to address the unattended needs of the patient.
\end{abstract}

\section{Introduction}

"Psoriasis is by nature a chronic, incurable disease which is used to describe autoimmune disorders of the skin that are characterized by an increased growth cycle of skin cells, resulting in the build-up of lesions psoriasis patients are bound to experience the ill effects of sorrow and nervousness issue and have an expanded pace of self-destructive ideation. Plaque psoriasis (psoriasis vulgaris), the most common subtype, and psoriatic arthritis (PsA) together are known as Psoriatic disease". 1,2

The consequence is often life-long treatment. Prevalence of psoriasis falls under range between 0.44 and $2.44 \%$ in developing countries like India. About $2-3 \%$ of population is affected by psoriasis worldwide. It more often than not influences in late 20's and mid 30's of age gathering, commonly affected age group is between 50 and 59. It is likely to affect twice in men as compared to women. ${ }^{3}$
"Medication Adherence is defined as the degree to which the behaviour of a patient correlate with the recommendations from a healthcare professional to which the patient agrees". ${ }^{2}$

Adherence to therapy is very important for the disease to get cured and restore the normal health. Non adherence is very commonly seen in patients with psoriasis due to various reasons such as lack of knowledge, economical factors, neglect fullness, forgetfulness etc. Even though there are many new discoveries in treatment, yet there is non-adherence. Early assessment of non-adherence factors is necessary to identify and improve adherence using new ways.

Screening at regular intervals for these associated diseases and for co-medication to prevent drug-drug interactions or drug-triggered psoriasis as well as recognition of trigger factors and their treatment are an essential part of psoriasis management. ${ }^{3}$ Lack of awareness about psoriasis and its associated co-morbidities results in under-diagnosis and

\footnotetext{
* Corresponding author. KLE College of Pharmacy, A Constituent Unit of KLE Academy of Higher Education and Research, Belagavi, India.

E-mail address: shashiwali90@gmail.com (S. Wali).
} 
ineffective therapy, inappropriate to the needs of the patient.

Non-adherence to treatment is a barrier to quality care for people with psoriasis. Multiple recurrences, side-effects and cost of treatment can dishearten patients. This can lead to poor adherence to therapy and prevent patients from achieving the best possible results from treatment. ${ }^{2}$ Hence, this study mainly aimed to assess the medication adherence with the help of pharmacist in patients with psoriasis, and to improve adherence by patient counselling, creating awareness of the disease to the patient.

\section{Materials \& methods}

A randomized controlled study was conducted in department of dermatology at tertiary care teaching hospital and medical research centre, for a duration for five months (November 2019-March 2020). Institutional ethical clearance was obtained from the human ethics committee of KLE college of pharmacy, Belagavi (Ref No; KLECOP/651/2018-19). Patients of age ranging between 18 and 65 of either sex, who were willing to involve in the study, and who have been diagnosed with psoriasis disease and on treatment were involved in the study. Patients with multiple co-morbidities like human immuno-deficiency virus, hepatitis $\mathrm{B} / \mathrm{C}$ and vulnerable population like lactating and pregnant women are excluded from the study.

8-Item Morisky Medication Adherence Scale (MMAS-8) was used to assess the medication adherence before and after intervention which was based on the Medication Adherence Questionnaire (MAQ), developed by Morisky et al. in 2008. "It contains eight questions, first 7 questions are yes/no responses and last 8th question has got 5 Likert response.“3

Schematic Representation:

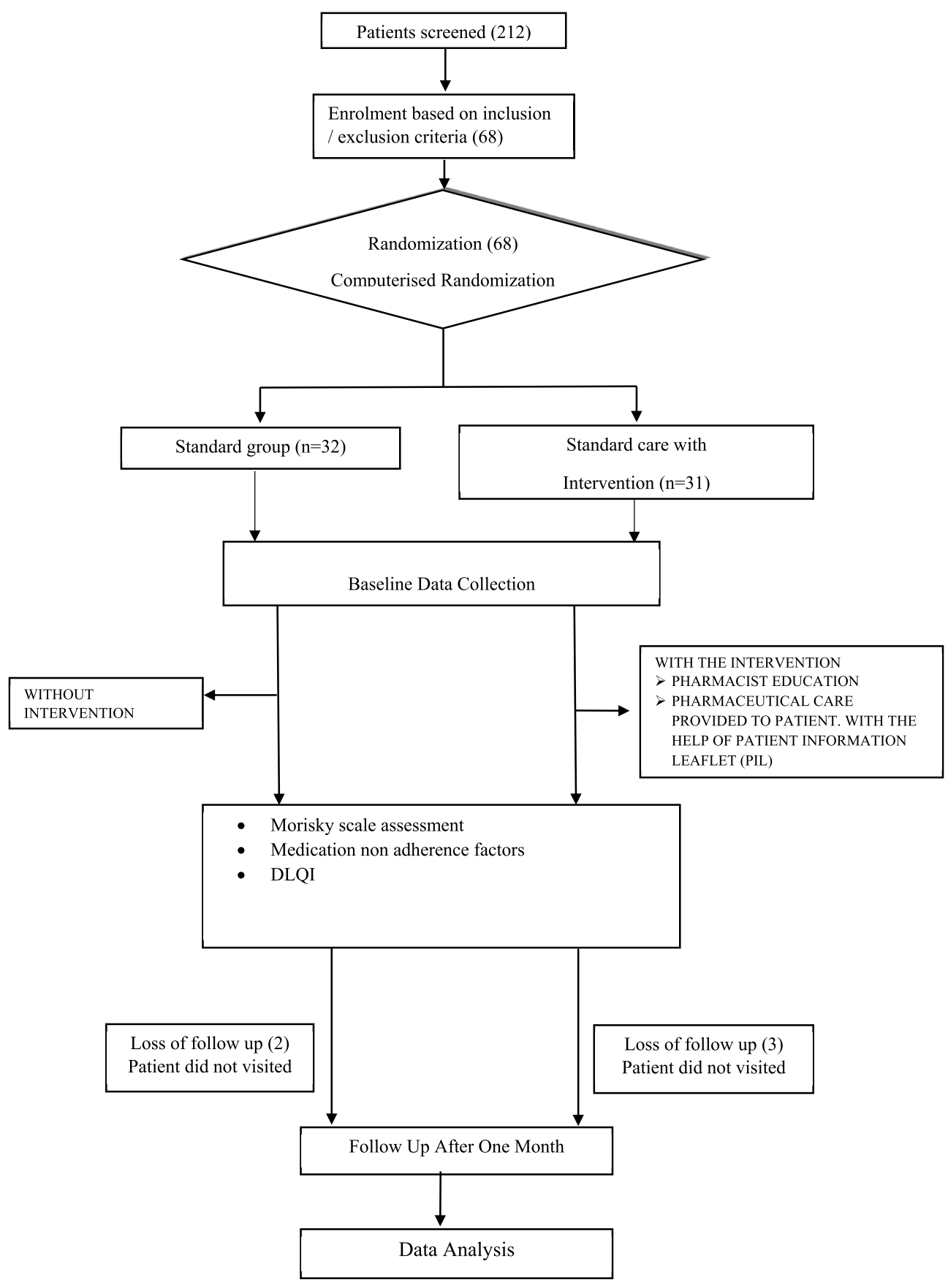




\section{Intervention}

All the patients included in the study were followed frequently with telephonic calls and follow up visits to dermatology outpatient department. This intervention group received standard care as well as pharmaceutical care from the clinical pharmacist regarding the importance of medication adherence and how it reflects in management and cure of the disease. Patient information leaflet was provided along with patient education in languages which patient is comfortable. Clinical pharmacist assessed the parameters like medication adherence (MMAS-8) at baseline and after one month of follow up.

\section{Data collection}

The data collection was carried out with the questionnaire using MMAS- 8 item questionnaire scale to assess the medication adherence. The patient complaints, medication history, current medication, types of psoriasis, present health status were noted on data collection form. Additional information related to patient's medical records, information provided by patients were recorded \& documented in data collection form.

\section{Statistical analysis}

The data was entered in excel sheet and analysed in SPSS (IBM version 22.0). Socio-demographics variable are summarized using descriptive statistics and the medication adherence between pre and post intervention was analysed using Mann Whitney $U$ test and Wilcoxon Matched Pair test.

\section{Results}

Total 68 patients were enrolled out of which 63 patients completed study successfully. There was not much difference in male $\mathrm{n}=31$ (49.21\%) and Female $\mathrm{n}=32(50.79 \%)$ in our study as shown in Table 1. The age group $50-59$ years $(n=18)$ were more prevalent and $18-29$ years $(n=7)$ were least prevalent in this study as depicted in Table 1 .

Chronic plaque psoriasis $74.60 \%(n=47)$ was most common and pustular psoriasis $1.59 \%(n=1)$ is the least common observed in this study. More details on types of psoriasis is given in Table 2 .

Medication adherence in control at baseline were mild adherence $46.88 \%$, moderate adherence $43.75 \%$ high adherence $9.38 \%$, experimental at baseline mild adherence $70.97 \%$, moderate $16.13 \%$ and high adherence $12.90 \%$. At the follow up there was significant difference of adherence in experiment group after post-test when compared with control.

Medication adherence in control at baseline were mild adherence 46.88\% ( $n=15)$, moderate adherence $43.75 \%(n=14)$ high adherence $9.38 \%(\mathrm{n}=3)$, experimental at baseline mild adherence $70.97 \%(\mathrm{n}=$

Table 1

Distribution of participants according to gender and age groups in control and experiment group.

\begin{tabular}{llll}
\hline & Control group (\%) & Experiment group (\%) & Total (\%) \\
\hline Gender & & & \\
Male & $17(53.13)$ & $14(45.16)$ & $31(49.21)$ \\
Female & $15(46.88)$ & $17(54.84)$ & $32(50.79)$ \\
Total & $32(100)$ & $31(100)$ & $63(100)$ \\
Chi-square $=0.4001 \mathrm{P}=0.5271$ & & \\
Age Groups & & $1(3.23)$ & $7(11.11)$ \\
$18-29$ & $6(18.75)$ & $9(29.03)$ & $15(23.81)$ \\
$30-39$ & $6(18.75)$ & $6(19.35)$ & $18(28.81)$ \\
$40-49$ & $9(28.13)$ & $9(29.03)$ & $74(10.70)$ \\
$50-59$ & $9(28.13)$ & $6(19.35)$ & \\
$60-65$ & $2(6.25)$ & $37(100)$ & \\
Total & $37(100)$ & & \\
Chi-square $=6.7572 \mathrm{P}=0.1491$ & & \\
\hline
\end{tabular}

Table 2

Comparison of control and experiment groups by types of psoriasis.

\begin{tabular}{llll}
\hline Types of psoriasis & $\begin{array}{l}\text { Control group } \\
(\%)\end{array}$ & $\begin{array}{l}\text { Experiment group } \\
(\%)\end{array}$ & Total (\%) \\
\hline $\begin{array}{l}\text { Chronic plaque } \\
\text { psoriasis }\end{array}$ & $25(78.13)$ & $22(70.97)$ & 47 \\
$\begin{array}{l}\text { Erythrodermic } \\
\text { Guttate psoriasis }\end{array}$ & $1(3.13)$ & $4(12.90)$ & $(74.60)$ \\
Palmoplantar psoriasis & $1(3.13)$ & $1(3.23)$ & $5(7.94)$ \\
Psoriatic arthritis & $0(0.25)$ & $0(0)$ & $2(3.17)$ \\
Pustular psoriasis & $0(0)$ & $2(6.45)$ & $2(3.17)$ \\
Scalp psoriasis & $3(9.38)$ & $1(3.23)$ & $2(3.17)$ \\
Total & $37(100)$ & $1(3.23)$ & $4(6.59)$ \\
Chi-square $=6.7572, \mathrm{P}=0.1491$ & $37(100)$ & 74 \\
\hline
\end{tabular}

Table 3

Comparison of control and experiment groups with medication adherence at pre-test and post-test treatment time point.

\begin{tabular}{llll}
\hline $\begin{array}{l}\text { Medication } \\
\text { adherence }\end{array}$ & Control group (\%) & Experiment group (\%) & Total (\%) \\
\hline $\begin{array}{l}\text { Pre-test } \\
\text { Mild adherence }\end{array}$ & $15(46.88)$ & $22(70.97)$ & $37(58.73)$ \\
$\begin{array}{l}\text { Moderate adherence } \\
\text { High adherence }\end{array}$ & $14(43.75)$ & $5(16.13)$ & $19(30.16)$ \\
$\begin{array}{l}\text { Post-test } \\
\text { Mild adherence }\end{array}$ & $3(9.38)$ & $4(12.90)$ & $7(11.11)$ \\
$\begin{array}{l}\text { Moderate adherence } \\
\text { High adherence }\end{array}$ & $8(25.00)$ & $0(0)$ & $20(31.75)$ \\
Total & $4(12.50)$ & $8(25.81)$ & $31(49.21)$ \\
\hline
\end{tabular}

22), moderate $16.13 \%(n=5)$ and high adherence $12.90 \%(n=4)$. At the follow up there was significant difference of adherence in experiment group after post-test when compared with control as represented in Table 3.

To evaluate the difference of pharmacist intervention between control and intervention group at different time points for medication adherence was analysed using Mann U Whitney test. At post-test there is significant difference between the control and intervention group ( $\mathrm{U}=$ 200.00, $\mathrm{p}$ value $=0.0001 *)$ as shown in Table 4 .

In control group there is only $7.69 \%$ of change in medication adherence concluding that there is not much difference between pre-test \& post-test $\mathrm{p}=0.3464(\mathrm{p}>0.05)$ where as in experimental group there is $59.09 \%$ of change in medication adherence indicating significant difference in pre-test and post-test after intervention $\mathrm{p}=0.0001(\mathrm{p}<$ 0.05 ) by using Wilcoxon Matched Pairs test as represented in Table 5.

\section{Discussion}

Interventional group (59.09\% change, $\mathrm{p}$ value $=0.0001 *)$ had a better adherence than control group $(7.69 \%$ change, $p$ value $=0.3464)$ after pharmacist intervention. Dario Nicolas Kivelevitch et al. ${ }^{4}$ showed a review was performed among 176 psoriasis patients at Fernandez emergency clinic at Buenos Aires, Argentina. $77 \%$ were observed to be non-adherent and 33\% were self-sedated. These 2 groups were about $82 \%$ of population examined.

Rod Tucker and Stewart D et al. ${ }^{5}$ conducted a study to evaluate the effect of education intervention delivered by community pharmacist in helping the patients with psoriasis for self-care. The important findings are pharmacist based intervention helped in increasing patients' knowledge about the disease, minimizing the severity of disease and ameliorating quality of life which was similar in our study where medication adherence had reflective improvement in interventional group after the follow-up as compared to the standard care $\mathrm{p}=0.0001$ ( $\mathrm{p}<0.05$ ). It demonstrates that there is explicating role of speciality pharmacist in increasing the medication optimization.

Zschocke, U, E. Karakasili1 K. Reich ${ }^{6}$ conducted a study in which the aim was to address non-adherence. The study stated that there was 
Table 4

Comparison of control and experiment groups with respect to Medication Adherence at pre-test and post-test time points by Mann-Whitney $U$ test.

\begin{tabular}{|c|c|c|c|c|c|c|c|c|c|c|c|}
\hline \multirow[t]{2}{*}{ Treatment } & \multicolumn{4}{|c|}{ Control group } & \multicolumn{4}{|c|}{ Experiment group } & \multirow[t]{2}{*}{ U-value } & \multirow[t]{2}{*}{ Z-value } & \multirow[t]{2}{*}{$\mathrm{p}$-value } \\
\hline & Mean & SD & Median & IQR & Mean & SD & Median & IQR & & & \\
\hline Pre-test & 1.63 & 0.66 & 2.00 & 0.50 & 1.42 & 0.72 & 1.00 & 0.50 & 397.00 & -1.3611 & 0.1735 \\
\hline Post-test & 1.50 & 0.72 & 1.00 & 0.50 & 2.26 & 0.44 & 2.00 & 0.50 & 200.00 & -4.0695 & $0.0001 *$ \\
\hline
\end{tabular}

$* \mathrm{p}<0.05$.

Table 5

Comparison of changes from pretest and posttest Medication adherence in two groups (Control and experiment) by Wilcoxon matched pairs test.

\begin{tabular}{|c|c|c|c|c|c|c|}
\hline Groups & Variables & Changes & $\%$ of change & T-value & Z-value & p-level \\
\hline Control & Medication adherence & Pretest to posttest & 7.69 & 37.50 & 0.9416 & 0.3464 \\
\hline Intervention & Medication adherence & Pretest to posttest & 59.09 & 9.50 & 3.9083 & $0.0001 *$ \\
\hline
\end{tabular}

$* \mathrm{p}<0.05$.

improvement in the medication adherence after the intervention. Intervention involved the active sessions, call reminders etc, similarly in this study proper patient education was provided to each patient to enhance the knowledge, importance of medication in disease improvement with the help of PIL. This helped the patient's in the interventional group reaching the goal of high adherence which is identical with this study. In our study, there was significant difference in pre-test and post-test in adherence after intervention signifying the value of clinical pharmacist's role in psoriasis management. Non-adherence to drugs is one of the main sources of treatment disappointment can incur unnecessary hospital re-admissions, multiple visits which can lead to ineffective treatment. $^{7}$

Identified disappointment with desired drug efficacy, side effects, and economic burden were the most imperative reasons proposed for non-compliance to the physician suggestions, which results in medication non-adherence. The disappointment with treatment adequacy was seen in our patient. ${ }^{8}$ Evaluation demonstrates that implausible desires for treatment might contribute non-adherence. ${ }^{9}$ Educating patients about the course of psoriasis on regular basis will help set up sensible desires for treatment. ${ }^{10,11}$

\section{Conclusion}

This study helps to bridge the gap in developing countries like in India where there is need for recognition as a speciality pharmacist who provides health care services diligently. This study had shown the positive impact among the participants which improves the outcomes and influences greater health benefits in the long term management of ineradicable diseases like psoriasis. Hence there is a need of clinical pharmacist in improving the affirmative health for betterment of unmet needs of the psoriasis patient.

\section{Funding}

The author(s) received no financial support for the research, authorship, and/or publication of this article.

\section{Acknowledgement}

We would like to thank Principal of JN Medical College, Superintendent of KLE Dr. Prabhakar Kore Charitable Hospital, Belagavi, MD of KLE Dr. Prabhakar Kore Hospital and Medical Research Centre, Belagavi, Principal KLE College of Pharmacy, Belagavi, and Department head of Dermatology, KLE Dr. Prabhakar Kore Hospital and Medical Research Centre, Belagavi.

\section{References}

1 Psoriasis centers for disease control and prevention; 2016. Updated February 9 www. Cdc.Gov/Psoriasis/. Accessed on July, 2018.

2 World Health Organization. Adherence to Long-Term Therapies: Evidence for Action. Geneva, Switzerland: World Health Organization; 2003.

3 Morisky DE, Green LW, Levine DM. Concurrent and predictive validity of a selfreported measure of medication adherence. Med Care. 1986;24:67-74.

4 Kivelevitch DN, Tahhan PV, Bourren P, Kogan NN, Gusis SE, Rodríguez EA. Selfmedication and adherence to treatment in psoriasis. Int J Dermatol. 2012;51(4): 416-419.

5 Tucker R, Stewart D. The role of community pharmacists in supporting selfmanagement in patients with psoriasis. Int J Pharm Pract. 2016;25(2):140-146.

6 Zschocke I, Mrowietz U, Karakasili E, Reich K. Non-adherence and measures to improve adherence in the topical treatment of psoriasis. J Eur Acad Dermatol Venereol. 2014;28:4-9.

7 Ahn CS, Culp L, Huang WW, Davis SA, Feldman SR. Adherence in dermatology. J Dermatol Treat. 2017;28(2):94-103.

8 Yeung H, Wan J, Van Voorhees AS, et al. Patient-reported reasons for the discontinuation of commonly used treatments for moderate to severe psoriasis. J Am Acad Dermatol. 2013;68(1):64-72.

9 Dommasch ED, Lee MP, Joyce CJ, Garry EM, Gagne JJ. Drug utilization patterns and adherence in patients on systemic medications for the treatment of psoriasis: a retrospective, comparative cohort study. J Am Acad Dermatol. 2018;79(6): 1061-1068. https://doi.org/10.1016/j.jaad.2018.06.053. e1.

10 Chand S, Shastry CS, Vinay BC, Bhandari R, et al. Brown, white and blue bagging in special pharmacy; an emerging trends to minimize medication errors. Journal of Global Pharma Technology. 2019;11(8):1-4.

11 Wali S, Mahantshetti NS, Ganachari MS, Parihar A, Bhandari R. Evaluation of antiepileptic medication adherence among paediatric epileptic patients: a randomized prospective study in a teaching hospital. International Journal of Pharmaceutical Research. Jul-Dec 2020;12(2):1078-1083. 